\title{
A Prospective Study of Adolescents' Peer Support: Gender Differences and the Influence of Parental Relationships
}

\author{
Lisa G. Colarossi ${ }^{1}$ and Jacquelynne S. Eccles $^{2}$
}

Received August 8, 1998; accepted May 14, 2000

This longitudinal study investigates parent and child predictors of adolescents' perceived social support from peers. Adolescents (285) and their parents filled out surveys when students were 11 and 15 years of age. Parent reports of their own social support and child reports of parental support to them, depression, and selfesteem were used as predictors of adolescents' peer social support. Path analyses revealed functional dissimilarity in the predictive model, for boys and girls. For boys and girls, the amount of spousal support parents' reported impacted the amount of parent to child support that children reported. For boys, this relationship impacted their perceptions of peer support indirectly through depression. However, for girls, parents' own supportive relationships directly impacted both their selfesteem and depression, above and beyond parent to child support, which then impacted girls' peer social support.

This research was funded by a grant from the National Institute of Child Health and Human Development (2R01HD17553-06) to Jacquelynne Eccles, Rena Harold, Allan Wigfield, and Phyllis Blumenfeld.

${ }^{1}$ Assistant Professor, Graduate School of Social Service, Fordham University, New York, New York. Received her Ph.D. in Social Work and Psychology from The University of Michigan. Research interests include gender differences in adolescent development and family processes, the nature and outcomes of social support, and applying research to policy and practice. To whom correspondence should be addressed at 113 West 60th Street, RM 725F, New York, NY 10025.

${ }^{2}$ Professor, Department of Psychology, The University of Michigan, Ann Arbor, Michigan 48109. Received her Ph.D. in Psychology from the University of California at Los Angeles. Research interests include social development, identity development, contextual influences on development, gender, and ethnicity. 


\section{INTRODUCTION}

Theory, research, and practice in the area of social support suggest that individuals who report high levels of social support in their relationships are in a better physical and mental health than those with low levels of support (see reviews by Barrera, 1986; Cohen and Wills, 1985; and Uchino et al., 1996). However, the type, amount, and providers of social support fluctuate with age and social context (Berndt and Perry, 1986; Feiring and Lewis, 1991; Kahn and Antonucci, 1980; Vaux, 1985), necessitating that individuals periodically form new relationships from which they may derive support. Those individuals who are skilled at developing supportive relationships can then derive more health benefits than those who are unable to build such relationships. Research has shown that, to some extent, individuals' social support is dependent on network characteristics, but individuals also possess personal qualities or characteristics that enable them to actively develop supportive relationships with others. Therefore, an important question arises: What individual experiences and characteristics predict the ability to develop supportive relationships over time?

Research with adolescents can provide important insights into this question. This is because adolescence is a transitional period for social support as teens move away from parents as their primary source of support and turn to peer relationships that will provide support as they take on adult roles (Slavin-Williams and Berndt, 1990; Youniss and Smollar, 1985). For example, research has found that social network composition changes with age such that children around the age of 10 receive more support from family members, wheras adolescents reported a larger number of, and more support from, friends (Degirmencioglu et al., 1998; Levitt et al., 1993). These results were comparable across gender and ethnic groups. Thus, longitudinal data from subjects at preadolescence and midadolescence can provide important information about the development of peer social support. Furthermore, adolescents' peer support has been linked to important developmental outcomes (Coates, 1985; Dubow et al., 1991; Slavin and Rainer, 1990), making it especially important to understand what factors predict peer support during adolescence.

However, when we look to the developmental literature, we see that supportive relationships, especially between peers, have been studied in large part, using adult samples. Children's peer relationships have been studied in terms of the presence or absence of friends and the identity of those friends (i.e., social groupings). Rarely have children's peer relationships been studied in terms of the social support they provide. Having friends is often equated with social skill development, rather than as part of a developmental process of supportive interpersonal relationships. Hartup (1996) argues for a more comprehensive understanding of children's friendships through distinguishing between having friends, the identity of the child's friends, and friendship quality. Moreover, he argues that friendship, quality in particular, may be more closely tied to individual differences than to whether or not the child has friends. 
Social support can be considered to be one aspect of friendship quality, and some studies have begun to consider the individual processes that predict adolescents' social support. For example, social support has been established as a predictor of mental health, but a developmental model would presume that this is not a unidirectional relationship. Family relationships and individual mental health also have the potential to affect one's ability to maintain supportive peer relationships. Research in this area is growing, but few researchers have examined childhood precursors of perceived social support from peers during adolescence. Also, there has been little published data on gender differences in the development of perceived social support in adolescents' peer relationships, even though descriptive studies have reported variations in social support by gender.

This study investigates parent and child precursors to adolescents' perceptions of social support from peers. It is an attempt to more fully develop knowledge about child and family processes and their developmental outcomes on social support, using longitudinal data and multiple reporters (e.g., parents and youth). The research model proposes that parents' relationships with each other and their own peers will positively impact the amount of support they provide to their child, and this will influence adolescents' mental health and their ability to form supportive relationships with peers later in life. The study also examines gender differences in the development of peer supports. The path model is shown in Fig. 1. The research hypotheses are (1) parents who perceive higher levels of support from their spouse and friends will have children (ages 11-13) who perceive more parental support; (2) children's perceived parental support will positively predict self-esteem and negatively predict depressive feelings 4 years later (ages 15-17), which will in turn be related to adolescent perceptions of peer support; (3) children's parental support will also positively affect adolescents' peer support later in life; and (4) gender differences will occur such that girls will report lower self-esteem and higher levels of depression than do boys, girls will report higher levels of peer support than do boys, and there will be significant interactions between student gender and the predictor variables in the regression model.

\section{Theoretical Framework and Related Research}

Ecological systems theory (Bronfenbrenner, 1979) and Kahn and Antonucci's Convoy Model of social support (Kahn and Antonucci, 1980) guide this study. They emphasize the importance of interpersonal interactions across various social systems (such as family and peers) that vary with life-course developmental needs, roles, and circumstances. From an ecological perspective, one would expect parents' and adolescents' psychological distress to be reciprocally interrelated (Bronfenbrenner, 1979; Compas and Wagner, 1991; Sameroff and Seifer, 1983). If parents are unable to obtain helpful supports from their own peers, their distress may impact the child and create unsupportive or even conflictual interactions between the parent and child over time. Alternately, family environments that provide 
developmentally appropriate opportunities and parental support for the child will influence positive developmental outcomes (Eccles, 1986). When parents' own peer contexts fit their needs for support, they may then be able to provide a better fit for their child's needs in the family context. It is also likely that parents' peer social support directly facilitates parenting through the provision of instrumental, informational, and emotional resources related to the parenting role.

Some researchers have begun to study how parents' own supportive relationships impact the amount and type of support they provide to their children. Although these studies have not examined parents' own peer support, parent to child support, child's mental health, and child's peer support in a combined model, research supports various aspects of these relationships and provides a foundation for developing a more complex model of the interrelations between parent and child contexts.

\section{Parents’ Peer Support and Parent to Child Support}

Research reflecting a skills-based perspective on social support has found that parents who receive ongoing support from a structured peer support group acquire better parenting skills over time in the group, including supportive behaviors toward their children; in turn, these children have better adjustment in a variety of behavioral, mental health, and academic areas (Dubow et al., 1991). Others have found that parents who are secure in their adult relationships adopt more flexible and adaptive parenting and are more successful at supporting their child's developmental transitions; whereas parents who cannot may function as a risk factor for depression and low self-esteem in children (Brage and Meredith, 1994; Durrett et al., 1986; Kobak and Ferenz-Gillies, 1995; Noller and Callahan, 1991). For example, Kobak and Ferenz-Gillies (1995) found that children who had difficulty asserting their own viewpoint during a conflict and whose parents were dissatisfied with their own intimate adult relationships reported increased levels of depression. Parents must manage intimacy and utilize support in their adult relationships to effectively provide supportive and appropriate parenting for teenagers. If parents are unable to manage their own adult concerns, teenagers may become vulnerable to depressive symptoms.

\section{Parental Support, Child's Mental Health, and Peer Relationships}

It has been proposed that perceptions of self and others involve overarching schema derived from specific relationships with parents. These schema directly and indirectly impact children's self-worth, their view of their parents, and their view of others (Sarason et al., 1993). Sarason et al. (1993, p. 1072) state, "From a developmental perspective, it is likely that receiving support, affection, and positive feedback from parents during the childhood years is a central source of positive self-image." And, in fact, research has demonstrated that self-esteem 
and depression in children are impacted by levels of support from parents. Depression has been consistently predicted by low levels of social support from family members (Barrera and Garrison-Jones, 1992; Holahan and Moos, 1987; Reinherz et al., 1989), whereas self-esteem is bolstered by high levels of support (Flaherty and Richman, 1986; Kobak and Sceery, 1988; Sroufe and Fleeson, 1986).

Additionally, many studies have linked the quality of spousal relationships to parents' interactions with their children and to outcomes of low self-esteem and depression in children later on. Most have found that the impact of conflict in the spousal relationship on depression and self-esteem in children is mediated by the extent to which the parent-child relationship is disrupted or impaired as a result of the spousal conflict (Amato, 1986; Barber, 1994; Furstenberg et al., 1987). Therefore, the extent to which parents' relationships enhance or disrupt parental support to the child will influence the child's mental health.

Furthermore, parental support has been found to influence the quality of children's close relationships with peers later in life (Flaherty and Richman, 1986; Kobak and Sceery, 1988; Sroufe and Fleeson, 1986). Peer relationships are also influenced by adolescents' mental health. For example, studies have found that depression is a strong negative predictor of perceptions of peer social support, whereas self-esteem is a positive predictor (Lakey, 1989; Lakey and Dickinson, 1994; Newcomb, 1990). Additionally, some studies have found gender differences in depressive symptomology and in levels of self-esteem, as well as in perceptions of support from parents and peers. In general, studies have found that girls report higher quantities of and greater satisfaction with peer support than boys do, but this difference has only seldom been found for support from family members (Berndt, 1982; Furman and Buhrmester, 1992; Jarvin and Nicholls, 1996; Slavin and Rainer, 1990; Vaux, 1985). However, support from family members does seem to have a greater impact on females' levels of depression and self-esteem than that on males (Cooper and Grotevant, 1987; Newcomb, 1990; Slavin and Rainer, 1990; Windle, 1992). Additionally, mental health has been found to be a stronger predictor of peer support for females than for males (Newcomb, 1990; Sarason et al., 1986).

Although these studies show a general trend in relationships between the variables, gender differences in the development of social support remain equivocal. Most of the research on gender differences in support has used adult subjects, indicating a need for studies into adolescent gender differences in peer support. Also, several studies have investigated descriptive differences in males' and females' perceptions of support from family and peers and in reports of depression and self-esteem, but few have studied differences in the strength of the relationship between social support, family relationships, and mental health by gender.

This study integrates the earlier research findings into a new model predicting adolescents' peer support from childhood variables and investigates gender differences in the model. It uses a prospective design that considers the impact of parents' own supportive peer relationships on children's (ages 11-13) perceptions of parental support to them, and how these predict adolescents' (ages 15-17) 
supportive peer relationships later in life, directly and indirectly through depression and self-esteem.

\section{METHODS}

\section{Participants}

This study analyzes data from the 4th and 5th waves of a large scale, longitudinal study of child and adolescent development conducted by Jacquelynne Eccles and her colleagues (Eccles et al., 1984; Eccles et al., 1990). We will further refer to these waves as Time 1 and Time 2 . The study was conducted in 4 primarily white, lower-middle to middle class school districts in midwestern suburban communities. Children's surveys were administered in the public schools by our research staff, and parent surveys were mailed to their home and returned upon completion.

Participants included 285 children (137 boys and 148 girls) and their parents (175 mothers and 110 fathers). At Time 1, children were in the 6th grade (ages 11-13 years, $M=11.5$ ). Time 2 data were collected 4 years later when the children were in 10th grade (ages 15-17). Ninety percent of these families identified themselves as Caucasian, 3\% as Asian American, 3\% as Arab American, 2\% as African American or Hispanic, and 2\% did not identify themselves as belonging to any racial category. Eighty-five percent of families reported their religious preference as some form of Christianity, $13 \%$ as having no particular preference or practice, and 2\% reported Jewish, Muslim, or Hindu preferences. Ninety-five percent of parents were married to their child's biological parent at Time 1, and most families reported incomes over $\$ 40,000 /$ year $(47 \%>\$ 40,000,5 \%<\$ 40,000$, $48 \%=$ no report). Chi-square analyses revealed no sex differences in any of these demographic characteristics.

Approximately equal numbers of mothers (175) and fathers (110) were randomly selected for analysis to represent a variety of parental perspectives on social support. Mothers' responses were selected for participants with even identification numbers, and fathers' responses were selected for participants with odd identification numbers. If the selected parent did not answer a survey, the parent who did answer was selected for analysis in his or her place (hence the larger number of mother over father participants). Chi-square analyses revealed no differences by child's sex or family income for those students whose fathers versus mothers were analyzed. Differences between mother and father reports of social support will be reported in the results.

Only those students who had both Time 1 and Time 2 data were selected for analysis. Eighty-seven students (23\% of the original Time 1 sample) were dropped from analysis because they had only completed Time 1 surveys. Chisquare analyses were performed to test for significant differences between subjects who dropped out after Time 1 and those who remained. These tests showed no 
significant differences by race, sex, parents' marital status, religion, or household income. Also, many of these subjects remained in our study after Time 2 and participated in later waves of surveys. This information would indicate that subjects who dropped out at Time 2 were not characteristically different from those who did not. Their attrition was likely due to being absent from school or participating in an alternate school activity on the day the surveys were administered.

\section{Measures}

All measures used 7-point Likert scales except the rating of self-esteem, which used a 4-point scale. Scores of ' 1 ' always designated a low rating for each item in the analyses. Scales were built by computing the uniweighted mean of all selected items. Reliabilities presented are Cronbach alphas. Social support scales measure subjects' perceptions of support rather than received or enacted support.

\section{Parents' Friend Support and Spousal Support}

Time 1 parent measures are parents' friend support and spousal support. Parents' friend support is a 2-item measure reflecting standard measures of adult support ( $\alpha=.74)$ : "How satisfied are you with the emotional support you receive from your friends?" and "How confident are you that you could turn to your friends for emotional and/or financial support in an emergency?" Spousal support is a 3 -item measure similar to the preceding friend support items $(\alpha=.88)$. Although these scales have fewer items than would be ideal, these measures have good internal consistency, clear face validity, and significant correlations with other survey measures commonly used to validate social support scales (e.g., friend support and depression $r=-.46$, anxiety $r=-.27$, life satisfaction $r=.30$; spousal support and depression $r=-.15$, anxiety $r=-.15$, life satisfaction $r=$ .38. $p<.05$ for all except where $r=-.15, p=.07$ ). Additionally, factor analyses revealed that support from relatives, friends, and spouse loaded separately from each other according to traditional indicators of eigenvalues and skee tests.

\section{Child's Parent Support}

Time 1 child's parent support is a 6-item scale from the Iowa Youth and Families Inventory (Conger et al., 1986) that measures children's perceptions of how often their mother and father provide support to them. These items include, "In the past month, how often did your mom listen carefully to your point of view?" and "In the past month, how often did your mom let you know she really cares about you?" Items also asked about perceptions of father support, and the items are combined into 1 scale $(\alpha=.83)$. 


\section{Adolescent Depression and Self-Esteem}

Time 2 depression is a 12-item measure from the Symptoms Checklist Revised (SLC-90-R; Derogatis, 1983). It is a measure of depressive affect rather than of diagnostic criteria for clinical depression. The scale was found to have good reliability ( $\alpha=.89$ ). Time 2 self-esteem (Harter, 1982) is a 7-item scale that includes, "How often do you feel happy with the way you are?" "How often are you pretty sure that you are a good person?" and "How often do you feel good about the way you act?" The original forced-choice scale format was converted to Likert-type items for scale creation $(\alpha=.75)$.

\section{Adolescent Peer Support}

Time 2 adolescents' peer support was created from items that were adapted and revised for friendship contexts from Csikszentmihalyi and Nakamura's concepts (Csikszentmihalyi and Nakamura, 1989) of feelings and cognitions in academic contexts such that questions asking about "school" experiences were changed to ask about "friends." Factor analyses, using traditional indicators of factor structure (eigenvalues and skree test), revealed a 5-item factor that theoretically fit with conceptualizations of emotionally and instrumentally supportive relationships with friends that were separate from support in school and family contexts. Examples of these items include, "When you have a personal problem, how often can you depend on your friends to help you out?" "How often do you feel good about yourself while you are hanging out with your friends?" and "How often do you feel left out when you are with your friends?" (Scale $\alpha=.72$ ).

\section{RESULTS}

\section{Parents' Social Support}

The means, standard deviations, and $T$-tests comparing mothers and fathers on the 2 aspects of parents' supportive relationships are presented in Table I. Parents' perceptions of spousal support and friend support range from 1 (not at all satisfied) to 7 (very satisfied). Both measures have negatively skewed distributions

Table I. Means, Standard Deviations, and $T$-Tests for Parent Measures

\begin{tabular}{|c|c|c|c|c|c|c|c|c|}
\hline & \multicolumn{2}{|c|}{$\begin{array}{l}\text { Whole sample } \\
\quad(n=285)\end{array}$} & \multicolumn{2}{|c|}{$\begin{array}{l}\text { Mothers } \\
(n=175)\end{array}$} & \multicolumn{2}{|c|}{$\begin{array}{c}\text { Fathers } \\
(n=110)\end{array}$} & \multirow[b]{2}{*}{$t$} & \multirow[b]{2}{*}{$p$} \\
\hline & $M$ & $\mathrm{SD}$ & $M$ & SD & $M$ & SD & & \\
\hline Parents' spousal support & 5.5 & 1.7 & 5.4 & 1.8 & 5.8 & 1.5 & -1.8 & .06 \\
\hline Parents' friend support & 5.0 & 1.5 & 5.2 & 1.6 & 4.7 & 1.2 & 2.5 & .01 \\
\hline
\end{tabular}


Table II. Means, Standard Deviations, and $T$-Tests for Child Measures

\begin{tabular}{|c|c|c|c|c|c|c|c|c|}
\hline & \multicolumn{2}{|c|}{$\begin{array}{l}\text { Whole sample } \\
\quad(n=285)\end{array}$} & \multicolumn{2}{|c|}{$\begin{array}{l}\text { Females } \\
(n=148)\end{array}$} & \multicolumn{2}{|c|}{$\begin{array}{c}\text { Males } \\
(n=137)\end{array}$} & \multirow[b]{2}{*}{$t$} & \multirow[b]{2}{*}{$p$} \\
\hline & $M$ & SD & $M$ & SD & $M$ & SD & & \\
\hline Child's parent support & 4.9 & 1.3 & 4.8 & 1.2 & 5.0 & 1.4 & -1.4 & .15 \\
\hline Child depression & 3.1 & 1.1 & 3.1 & 1.1 & 3.0 & 1.1 & 0.7 & .49 \\
\hline Child self-esteem & 3.1 & 0.5 & 2.9 & 0.6 & 3.2 & 0.5 & -2.9 & .00 \\
\hline Child's peer support & 5.6 & 0.9 & 5.8 & 0.8 & 5.5 & 1.0 & 2.6 & .01 \\
\hline
\end{tabular}

and high modes (spousal support mode $=7$; parents' friend support mode $=5$ ), indicating that parents are mostly very satisfied with the support they receive from their spouse and their friends. Fathers report higher spousal satisfaction than do mothers, although this difference did not attain significance, $t(276)=-1.8$, $p=.06$, whereas mothers report greater satisfaction with friend support than do fathers $(t(277)=2.50, p=.01)$.

\section{Children's Parental Support}

Means, standard deviations, and $T$-tests by child sex for all child variables are presented in Table II. Time 1 parental support ranges from 1 (almost never) to 7 (everyday) and scores are normally distributed. No significant gender differences were revealed in $T$-tests between boys' and girls' perceptions of parental support. Additional $T$-tests revealed that no significant differences exist between boys and girls in the amount of support they perceive from mothers and fathers separately, and they did not report differences in the amount of support from mothers relative to fathers in general. Therefore, mother and father support is used as a combined measure of "parent support."

\section{Adolescents' Mental Health}

Time 2 adolescent self-esteem ranges from 1 (low) to 4 (high) and is normally distributed. Girls' scores are significantly lower than that of boys, $t(228)=-2.88$, $p=.004$. Time 2 depression scores range from 1 (low) to 7 (high) and are slightly positively skewed. No significant gender differences were found for depression.

\section{Adolescents' Perceived Peer Support}

At Time 2, adolescents perceive peer support as relatively high overall, with a range of 2.8-7 and a slightly negatively skewed distribution. Girls report significantly higher satisfaction with support from peers than do boys, $t(232)=2.61$, $p=.01$. 
Table III. Pearson Product-Moment Correlations: Total Sample and Separately By Student Sex

\begin{tabular}{|c|c|c|c|c|c|}
\hline & $\begin{array}{c}\text { Parents' } \\
\text { spousal support }\end{array}$ & $\begin{array}{c}\text { Parents' } \\
\text { friend support }\end{array}$ & $\begin{array}{l}\text { Parent-child } \\
\text { support }\end{array}$ & $\begin{array}{c}\text { Adolescent } \\
\text { depression }\end{array}$ & $\begin{array}{l}\text { Adolescent } \\
\text { self-esteem }\end{array}$ \\
\hline \multicolumn{6}{|l|}{ Total sample } \\
\hline Parents' friend support & -.00 & - & & & \\
\hline Parent to child support & $.20^{* *}$ & .11 & - & & \\
\hline Child depression & -.03 & -.10 & $-.17^{* *}$ & - & \\
\hline Adolescent self-esteem & $.13^{*}$ & $.23^{* *}$ & $.15^{*}$ & $-.53^{* *}$ & - \\
\hline Adolescent peer support & .04 & .07 & .11 & $-.43^{* *}$ & $.37^{* *}$ \\
\hline \multicolumn{6}{|l|}{ Females } \\
\hline Parents' friend support & -.05 & - & & & \\
\hline Parent to child support & $.39^{* *}$ & .04 & - & & \\
\hline Adolescent depression & $-.19^{*}$ & $-.30^{* *}$ & $-.20 *$ & - & \\
\hline Adolescent self-esteem & .18 & $.24^{*}$ & .16 & $-.65^{* *}$ & - \\
\hline Adolescent peer support & .12 & .09 & $.20^{*}$ & $-.47^{* *}$ & $.54^{* *}$ \\
\hline \multicolumn{6}{|l|}{ Males } \\
\hline Parents' friend support & .06 & - & & & \\
\hline Parent to child support & $.23^{*}$ & .10 & - & & \\
\hline Adolescent depression & .12 & .08 & -.15 & - & \\
\hline Adolescent self-esteem & .03 & .16 & .08 & $-.41^{* *}$ & - \\
\hline Adolescent peer support & .00 & .09 & .10 & $-.41^{* *}$ & $.32^{* *}$ \\
\hline
\end{tabular}

\section{Predictive Model}

Table III presents correlations between the predictors and outcome variables for the whole sample and separately by child sex. An analysis of these correlations indicates that the predictors are not highly intercorrelated, indicating that the measures are separate and distinct from each other and should not pose a serious multicolliniarity problem for regression analyses. Recursive path analysis is used to test the causal model, which consists of a series of 4 multiple regressions. Each dependent variable is regressed on all variables previous to it in the causal chain, and independent and mediated effects are tested. The exogenous variables are Time 1 parents' friend support and spousal support. Mediating variables are Time 1 child's parent support and Time 2 self-esteem and depression. The dependent variable is Time 2 peer support. Regressions are analyzed for the whole sample and separately for boys and girls. Figure 1 presents the hypothesized causal model.

The model significantly predicted adolescents' perceptions of peer support for the whole sample $\left(R^{2}=.21, p=.0000\right)$ and separately for girls $\left(R^{2}=.32, p=\right.$ $.0000)$ and boys $\left(R^{2}=.20, p=.0001\right)$. To test whether the models significantly differed for males and females, additional simultaneous regression equations were calculated for the whole sample where each dependent variable in the causal chain is regressed on the original predictors, sex, and the interaction of sex with each of the original predictors. The results reveal that at each stage of the path analysis, sex or the interaction terms or both of the are significant predictors (see Table IV), indicating that the slopes of the 2 groups are significantly different (Lautenschlager 


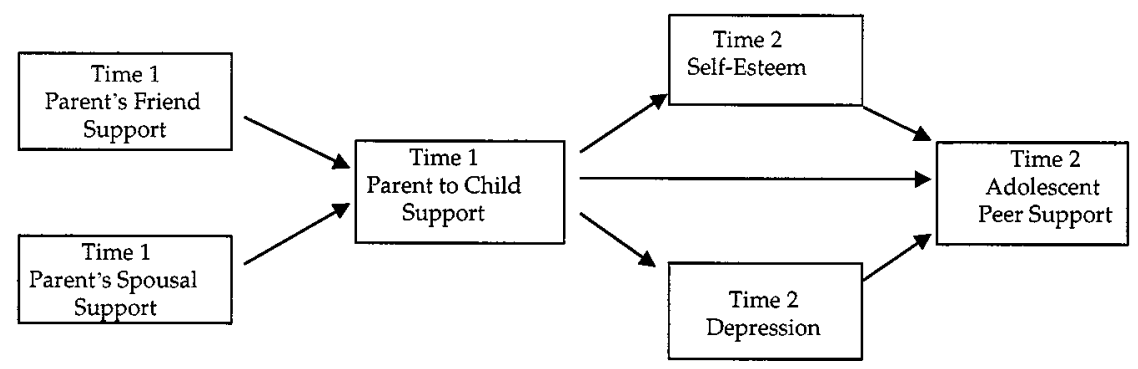

Fig. 1. Predicted model.

and Mendoza, 1986). This finding, in addition to the differences in which variables contributed to child's friend support in the male and female models separately, indicated functional dissimilarity in the developmental paths of boys' and girls' peer support.

Table $\mathrm{V}$ presents the unstandardized Beta coefficients and $R$-squared results separately by child sex. The results for girls indicate that parents' spousal support has a large, significant impact on parent to child support $(B=.28, p<.001)$

Table IV. Direct and Interactive Effects of Predictor Variables and Student Sex

\begin{tabular}{|c|c|c|c|}
\hline Predicted variable & Equation variable & Standarized beta & Significance level $(p)$ \\
\hline \multirow[t]{5}{*}{ Parent to child SS } & Spousal SS & .35 & .0001 \\
\hline & Spousal SS $\times$ Sex & .52 & .01 \\
\hline & Parents' friend SS & .25 & .005 \\
\hline & Parents' friend SS $\times$ Sex & .19 & n.s. \\
\hline & Child sex & .63 & .07 \\
\hline \multirow[t]{7}{*}{ Depression } & Spousal SS & -.14 & n.s. \\
\hline & Spousal SS $\times$ Sex & .76 & .0001 \\
\hline & Parents' friend SS & -.27 & .002 \\
\hline & Parents' friend SS $\times$ Sex & .58 & .02 \\
\hline & Parent to child SS & -.13 & .06 \\
\hline & Parent to child $\mathrm{SS} \times \mathrm{Sex}$ & -.60 & .0001 \\
\hline & Child sex & -.66 & .05 \\
\hline \multirow[t]{7}{*}{ Self-esteem } & Spousal SS & .17 & .07 \\
\hline & Spousal SS $\times$ Sex & -.34 & n.s. \\
\hline & Parents' friend SS & .25 & .005 \\
\hline & Parents' friend SS $\times$ Sex & -.19 & n.s. \\
\hline & Parent to child SS & .08 & n.s. \\
\hline & Parent to child SS $\times$ Sex & .03 & n.s. \\
\hline & Child sex & .63 & .07 \\
\hline \multirow[t]{6}{*}{ Adolescents' peer SS } & Spousal SS & .01 & n.s. \\
\hline & Parents' friend SS & .01 & n.s. \\
\hline & Parent to child SS & .03 & n.s. \\
\hline & Depression & -.29 & .0000 \\
\hline & Self-esteem & .27 & .0002 \\
\hline & Child sex & -.21 & .0007 \\
\hline
\end{tabular}

Note. Interaction terms are not significant. SS: social support. 
Table V. Regression Path Analyses Separately by Student Sex

\begin{tabular}{|c|c|c|c|c|}
\hline Predicted variable & Equation variable & Beta & $R_{\text {change }}^{2}$ & $R_{\text {total }}^{2}$ \\
\hline \multicolumn{5}{|l|}{ For females } \\
\hline \multirow{2}{*}{ Parent-child SS } & Parents'spousal SS & $.28^{* * *}$ & .15 & \\
\hline & Parents' friend SS & .05 & .00 & $.15^{* * *}$ \\
\hline \multirow[t]{3}{*}{ Depression } & Parent-child SS & -.09 & .03 & \\
\hline & Parents' friend SS & $-.21^{* *}$ & .08 & \\
\hline & Parents' spousal SS & -.10 & .03 & $.13^{* *}$ \\
\hline \multirow[t]{3}{*}{ Self-esteem } & Parent-child SS & .03 & .02 & \\
\hline & Parents' friend SS & $.09 *$ & .05 & \\
\hline & Parents' spousal SS & .06 & .02 & $.09^{*}$ \\
\hline \multirow[t]{5}{*}{ Adolescents' peer SS } & Depression & $-.17^{*}$ & .22 & \\
\hline & Self-esteem & $.55^{* * *}$ & .09 & \\
\hline & Parent-child SS & .08 & .01 & \\
\hline & Parents' friend SS & -.04 & .00 & \\
\hline & Parents' spousal SS & -.03 & .00 & $.32^{* * *}$ \\
\hline \multicolumn{5}{|l|}{ For males } \\
\hline \multirow[t]{2}{*}{ Parent-child SS } & Parents' spousal SS & $.19^{* *}$ & $.05^{* *}$ & \\
\hline & Parents' friend SS & .08 & .01 & $.06^{*}$ \\
\hline \multirow[t]{3}{*}{ Depression } & Parent-child SS & $-.17^{*}$ & .02 & \\
\hline & Parents' friend SS & .08 & .03 & \\
\hline & Parents' spousal SS & .12 & .01 & .06 \\
\hline \multirow[t]{3}{*}{ Self-esteem } & Parent-child SS & .03 & .01 & \\
\hline & Parents' friend SS & .05 & .02 & \\
\hline & Parents' spousal SS & .003 & .00 & .03 \\
\hline \multirow[t]{5}{*}{ Adolescents' peer SS } & Depression & $-.32^{* * *}$ & $.16^{* * *}$ & \\
\hline & Self-esteem & .38 & .03 & \\
\hline & Parent-child SS & .02 & .00 & \\
\hline & Parents' friend SS & .07 & .01 & \\
\hline & Parent's spousal SS & .02 & .00 & $.20^{* * *}$ \\
\hline
\end{tabular}

Note. SS: social support; Beta: unstandardized Beta coefficient.

${ }^{*} p<.05 ;{ }^{* *} p<.01 ;{ }^{* * *} p<.001$.

and explains a significant amount of the variance $\left(R^{2}=.15, p<.001\right)$. However, parents' friend support does not have a significant effect over and above spousal support. Also, contrary to the predicted model, parent to child support does not have a significant impact on girls' depression, self-esteem, or perceptions of peer support 4 years later. Rather, parents' friend support alone significantly predicts girls' depression $(B=-.21, p<.01)$ and self-esteem $(B=.09, p<.05)$, which in turn have significant effects on adolescents' peer support $\left(B_{\text {depression }}=-.17\right.$, $\left.p<.05 ; B_{\text {esteem }}=.55, p<.001\right)$. Predictive paths for the boys' model are also different from those that were originally hypothesized. Parents' spousal support significantly impacts parent to child support ( $B=.19, p<.01)$, whereas parents' friend support does not. Parent to child support significantly affects boys' depression 4 years later $(B=-.17, p<.05)$, which in turn was the only significant predictor of adolescents' peer support for boys $(B=-.32, p<.001)$.

Table VI presents the direct, indirect, and total effects of each predictor on the outcome variable (adolescents' peer support) for the boys and girls models; 
Table VI. Direct, Indirect, and Total Effects of Each Predictor on Adolescent Peer Support: Separately by Student Sex

\begin{tabular}{llcr}
\hline Independent variable & Direct & Indirect & Total \\
\hline For females & & & \\
Parents' friend SS & & & \\
$\quad$ Through self-esteem & n.s. & .05 & .05 \\
$\quad$ Through depression & n.s. & .04 & .04 \\
Parents' spousal SS & & & \\
$\quad$ Through self-esteem & n.s. & .03 & .03 \\
$\quad$ Through depression & n.s. & .02 & .02 \\
Parent to child SS & & & \\
$\quad$ Through self-esteem & .08 & .02 & .10 \\
$\quad$ Through depression & .08 & .02 & .10 \\
Adolescent self-esteem & .55 & - & .55 \\
Adolescent depression & -.17 & - & -.17 \\
For males & & & \\
Parents' friend SS & & & .005 \\
$\quad$ Through self-esteem & n.s. & .01 & \\
$\quad$ Through depression & n.s. & -.03 & -.03 \\
Parents' spousal SS & & & .00 \\
$\quad$ Through self-esteem & n.s. & .00 &. .03 \\
$\quad$ Through depression & n.s. & -.03 & .03 \\
Parent to child SS & & & .09 \\
$\quad$ Through self-esteem & .02 & .01 & .38 \\
Through depression & .02 & .07 & -.32 \\
Adolescent self-esteem & .38 & - & \\
Adolescent depression & -.32 & - & \\
\hline
\end{tabular}

Note. SS: social support.

however, no true mediational effects were found in accordance with the statistical conditions outlined by Baron and Kenny (1986). These effects are reported to further consider the relative differences between boys' and girls' models, and to do this, unstandardized path coefficients are presented. I will describe the direct and indirect effects as relative sizes of the path coefficients rather than focusing on significance levels alone due to the influence of smaller sample size on the significance of the coefficients after splitting boys and girls into groups.

For boys, the largest influences on their perceptions of peer support come from the effect of depression, which are effected by parents' spousal satisfaction directly and indirectly through their perception of parental support to them. All of these paths were significant, whereas paths from the other variables were not. Boys' self-esteem has the next largest, although nonsignificant, impact on their perception of peer support, but their self-esteem is not significantly influenced by any of the predictor variables in the model.

For girls, the model appears to be more complex. The largest influences on their perception of friend support come from the effect of their self-esteem, which is impacted both by parents' spousal support and by parents' friend support, but not by girls' perceptions of support from their parents. The next greatest effect 
on their perceptions of peer support come from their levels of depression. Girls' levels of depression are directly impacted by their perceptions of parent support, parents' spousal support, and parents' friend support.

\section{DISCUSSION}

This study explored predictors of adolescents' social support from peers. The researchers hypothesized that parents' supportive relationships with each other and with their friends would positively influence the amount of support they provided to their child, in turn influencing their child's mental health and peer social support in adolescence. The path model considered influences in different directions than are usually studied. Most studies of social support focus on mental health outcomes, with support as a predictor variable. However, these relationships are probably reciprocal over time, such that declines in mental health can also affect interpersonal relationships with others. Therefore, this study broadens the research on social support by beginning to analyze influences on adolescents' peer support. Findings indicate functional dissimilarity in boys' and girls' statistical models. However, an ecological systems perspective of multilevel interactions was supported as parent contexts were found to affect child psychological and social outcomes, and child's mental health was related to their social relationships.

An initial investigation of descriptive differences in measures of parents' peer support revealed that mothers reported significantly more satisfaction with support from friends than did fathers, whereas fathers reported more satisfaction in support from their spouse than did mothers. These findings are congruent with other research findings that adult males are on average more satisfied in their spousal relationship than women are, and that women have more satisfying friendships outside of marriage than men have (Antonucci, 1983; Bell, 1981; Berndt, 1982; Hobfoll, 1986). Children's measures were also explored for mean-level gender differences. Girls reported significantly lower levels of self-esteem and higher levels of peer support than did boys, but no significant gender differences existed in perceptions of parental support or in depressive symptomology.

Regression results indicated functional dissimilarity in the developmental path of boys and girls for the effects of the predictor variables on peer support during adolescence. Across child gender, parents' own supportive relationships had an impact on their children's mental health over a 4-year period, and the resulting levels of depression and self-esteem had the greatest impact on adolescents' peer support. However, for girls, parents' own supportive relationships had an indirect impact on girls' adolescent peer relationships through depression and self-esteem, and, contrary to our hypothesis, parent-child support did not significantly impact girls' friendships or mental health. For boys, depression had the major influence on their friendship support, and this was significantly impacted only by their parent's spousal relationship and by their perceptions of parental support to them. 
This difference may indicate that boys' depression is impacted more directly from parental treatment of them and other nonfamilial factors, whereas girls' mental health is more sensitive to multiple relationship dynamics within the family. For example, girls might perceive their parents' own relationships in a way that it influences their mental health above and beyond their parents' direct support to them. If girls are more emotionally reactive to parents' own distress or happiness in their relationships, they could, in turn, incorporate these emotions into their own happiness or depression. This is also indicated by the significant impact of familial relationships on girls' self-esteem. Alternately, none of the variables in the model significantly predicted boys' self-esteem, which indicates that boys derive esteem from sources that are not as influenced by family relationships such as sports or academics. This would be consistent with theory and research regarding sex role socialization of boys toward mastery and exploration of the world and girls toward interpersonal relationships (Block, 1983; Harter, 1990). Gilligan and other theorists have suggested that there may be significant, pervasive differences in the way males and females experience and understand social and personal aspects of relationships with others (Bell, 1981; Gilligan, 1982; Slavin and Rainer, 1990). The research presented here provides some evidence for this view.

Another possible explanation may lie in parents' actual behaviors toward male and female children such as verbal messages that affect self-esteem, but aren't being captured in measurements of children's perceptions of the support they receive from their parents. What is clear is that more research is needed to elucidate the mechanisms by which parents' satisfaction in peer relationships affects their children's mental health. Using disaggregated measures of parents' provision of social support to their children may be helpful in sorting out what kinds of support (e.g., emotional, instrumental, informational, etc.) are being provided and if some types are more influenced by external factors or child gender than others are. Additionally, the mechanisms by which mental health affects adolescents' development of supportive relationships need clarification.

\section{Limitations and Future Needs}

To more fully understand the processes that influence the development of supportive relationships, this model should be elaborated in several ways in the future. First, other studies have shown that social support impacts mental health outcomes, and this study would be strengthened by the addition of another wave of data, measuring depression, self-esteem, and social support so that reciprocal influences could be analyzed over time. Second, the homogeneity of this study's sample poses some limitiations. If the quality of adult relationships is determined in part by earlier familial socialization experiences, research should devote greater attention to examining variability in parent-child relationships and interactional patterns associated with social-structural factors such as social class, ethnicity, and 
sex of the child. Third, parent and child cognitive variables should also be specified for their role in emotions and perceptions of social support. Some research has indicated that social support may be an individual difference variable based on cognitive "working models" of oneself and others (Pierce, Sarason, and Sarason, 1992). There is also some evidence to suggest that these belief systems are passed from parents to children (Antonucci and Akiyama, 1991; Reiss and Oliveri, 1983; Sarason et al., 1991). Further research into these areas will add to this study's findings that adolescents' peer support, which has been shown to be a protective factor for a number of developmental outcomes, can be influenced by both family processes and individual mental health factors.

\section{REFERENCES}

Amato, P. R. (1986). Father involvement and the self-esteem of children and adolescents. Austr. J. Sex, Marr. Fam. 7: 6-16.

Antonucci, T. C. (1983). Social support: Theoretical advances, recent findings, and pressing issues. In Sarason, I. G., and Sarason, B. R. (eds.), Social support: Theory, Research, and Applications. Martinus Nijhoff, Boston, pp. 21-38.

Antonucci, T. C., and Akiyama, H. (1991). Convoys of social support: Generational issues. Marr. Fam. Rev. 16(1/2): 103-123.

Barber, B. L. (1994). Support and advice from married and divorced fathers. Fam. Rel. 43: 433-438.

Baron, R. M., and Kenny, D. A. (1986). The moderator-mediator variable distinction in social psychological research: Conceptual, strategic, and statistical considerations. J. Person. Soc. Psychol. 51(6): 1173-1182.

Barrera, M. (1986). Distinctions between social support concepts, measures, and models. Am. J. Commun. Psychol. 14: 413-445.

Barrera, M., and Garrison-Jones, C. (1992). Family and peer social support as specific correlates of adolescent depressive symptoms. J. Abnorm. Child Psychol. 20: 1-16.

Bell, R. R. (1981). Worlds of Friendship. Sage Publications, Beverly Hills.

Berndt, T. J. (1982). The features and effects of friendship in early adolescence. Child Dev. 53(6): 1447-1460.

Berndt, T. J., and Perry, T. B. (1986). Children's perceptions of friendships as supportive relationships. Develop. Psychol. 22(5): 640-648.

Block, J. H. (1983). Differential premises arising from differential socialization of the sexes: Some conjectures. Child Dev. 54: 1335-1354.

Bronfenbrenner, U. (1979). The Ecology of Human Development: Experiments by Nature and Design. Harvard University Press, Cambridge, MA.

Brage, D., and Meredith, W. (1994). A causal model of adolescent depression. J. Psychol. 128(4): 455-468.

Coates, D. (1985). Relationships between self-concept measures and social network characteristics for Black adolescents. J. Early Adolesc. 5: 319-338.

Cohen, S., and Wills, T. A. (1985). Stress, social support, and the buffering hypothesis. Psychol. Bull. 98(2): 310-357.

Compas, B. E., and Wagner, B. M. (1991). Psychological stress during adolescence: Intrapersonal and interpersonal processes. In Colten, M. E., and Gore, S. (eds.), Adolescent Stress: Causes and Consequences. Aldine de Gruyter, New York, pp. 67-86.

Conger, R. D., Brainerd, D. W., Birch, L. L., and Friedberg, P. J. (1986). Assessing the quality of family observations: A comparative analysis. J. Marr. Fam. 48(2): 361-373.

Cooper, C. R., and Grotevant, H. D. (1987). Gender issues in the interface of family experience and adolescents' friendship and dating identity. J. Youth Adolesc. 16(3): 247-264.

Csikszentmihalyi, M., and Nakamura, J. (1989). In Ames, R. E., and Ames, C. (eds.), Research on Motivation in Education: Goals and Cognition. Academic Press, New York. 
Degirmencioglu, S. M., Urber, K. A., Tolson, J. M., and Richard, P. (1998). Adolescent friendship networks: Continuity and change over the school year. Merrill-Palmer Q. 44(3): 313-337.

Derogatis, L. R. (1983). SCL-90-R Administration, Scoring, and Procedures Manual. Johns Hopkins University, Baltimore.

Dubow, E. F., Tisak, J., Causey, D., Hryshko, A., and Reid, G. (1991). A two-year longitudinal study of stressful life events, social support, and social problem-solving skills: Contributions to children's behavioral and academic adjustment. Child Dev. 62: 583-599.

Durrett, M. E., Richards, P., Otahi, M., and Pennebaker, J. W. (1986). Mother's involvement with infant and her perception of spousal support: Japan and America. J. Marr. Fam. 48(1): 187-194.

Eccles, J. S. (1986). Person-environment fit in early adolescence. Paper presented at the annual meeting of the American Educational Research Association, San Francisco, April 1986.

Eccles, J. S., Blumenfeld, P. C., Harold, R. D., and Wigfield, A. L. (1990). Ontongeny of self and task concepts and activity choice (Grant No. 2 R01 HD17553-06). National Institute of Child Health and Human Development, Bethesda, Maryland.

Eccles, J. S., Wigfield, A. L., and Blumenfeld, P. C. (1984). Psychological predictors of competence development (Grant No. 2 R01 HD17553-01). National Institute of Child Health and Human Development, Bethesda, Maryland.

Feiring, C., and Lewis, M. (1991). The development of social networks from early to middle childhood: Gender differences and the relation to school competence. Sex Roles 25(3/4): 237-253.

Flaherty, J. A., and Richman, J. A. (1986). Effects of childhood relationships on the adult's capacity of form social supports. Am. J. Psychiat. 143(7): 851-855.

Furman, W., and Buhrmester, D. (1992). Age and sex differences in perceptions of networks of personal relationships. Child Dev. 63: 103-115.

Furstenberg, F. F., Morgan, S. P., and Allison, P. D. (1987). Paternal participation and children's wellbeing after marital dissolution. Am. Sociol. Rev. 52: 695-701.

Gilligan, C. (1982). In a Different Voice: Psychological Theory and Women's Development. Harvard University Press, Cambridge, MA.

Harter, S. (1982). Perceived competence scale for children. Child Dev. 53: 87-97.

Harter, S. (1990). Self and identity development. In Feldman, S. S., and Elliott, G. R. (eds.), At the Threshold: The Developing Adolescent. Harvard University Press,Cambridge, MA, pp. 352387.

Hartup, W. W. (1996). The company they keep: Friendships and their developmental significance. Child Dev. 67: 1-13.

Hobfoll, S. E. (1986). Stress, Social Support, and Women. Hemisphere Publishing Corp, New York.

Holahan, C. J., and Moos, R. H. (1987). Risk, resistance, and psychological distress: A longitudinal analysis with adults and children. J. Abnorm. Psychol. 96: 3-13.

Jarvin, D. W., and Nicholls, J. G. (1996). Adolescents' social goals, beliefs about the causes of social success, and satisfaction in peer relations. Develop. Psychol. 32(3): 435-441.

Kahn, R. L., and Antonucci, T. C. (1980). Convoys over the life course: Attachment, roles and social support. In Baltes, P., and Brim, O. (eds.), Life Span Development and Behavior (Vol. 3). Academic Press, San Diego, CA, pp. 253-286.

Kobak, R., and Ferenz-Gillies, R. (1995). Emotion regulation and depressive symptoms during adolescence: A functionalist perspective. Dev. Psychopathol. 7: 183-192.

Kobak, R. R., and Sceery, A. (1988). Attachment in late adolescence: Working models, affect regulation, and representations of self and others. Child Dev. 59: 135-146.

Lakey, B. (1989). Personal and environmental antecedents of perceived social support developed at college. Am. J. Commun. Psychol. 17(4): 503-519.

Lakey, B., and Dickinson, L. G. (1994). Antecedents of perceived support: Is perceived family environment generalized to new social relationships? Cognit. Ther. Res. 18(1): 39-53.

Lautenschlager, G. J., and Mendoza, J. L. (1986). A step-down hierarchical multiple regression analysis for examining hypotheses about test bias in prediction. Appl. Psychol. Measure. 10: 133139.

Levitt, M. J., Guacci-Franco, N., and Levitt, J. L. (1993). Convoys of social support in childhood and early adolescence: Structure and function. Develop. Psychol. 29(5): 811-818.

Newcomb, M. D. (1990). Social support and person characteristics: A developmental and interactional perspective. J. soc. clin. psychol. 9(1): 54-68.

Noller, P., and Callahan, C. (1991). The Adolescent in the Family. Routledge, London. 
Pierce, G. R., Sarason, B. R., and Sarason, I. G. (1992). General and specific support expectations and stress as predictors of perceived supportiveness: An experimental study. J. Person. Soc. Psychol. 63(2): 297-307.

Reinherz, H. Z., Stewart-Berghauer, G., Pakiz, B., Frost, A. K., Moeykens, B. A., and Holmes, W. M. (1989). The relationship of early risk and current mediators to depressive symptomatology in adolescence. J. Am. Acad. Child Adoles. Psychiat. 28: 942-947.

Reiss, D., and Oliveri, M. E. (1983). The family's construction of social reality and its ties to its kin network: An exploration of causal direction. J. Marr. Fam. 2: 81-91.

Sameroff, A. J., and Seifer, R. (1983). Familial risk and child competence. Child Dev. 54: 1254-1268.

Sarason, B. R., Pierce, G. R., Bannerman, A., and Sarason, I. G. (1993). Investigating the antecedents of perceived social support: Parents' views of and behavioral toward their children. J. Person. Soc. Psychol. 66(5): 1071-1085.

Sarason, B. R., Pierce, G. R., Shearin, E. N., Sarason, I. G., and Waltz, J. A. (1991). Perceived social support and working models of self and actual others. J. Person. Soc. Psychol. 60(2): 273-287.

Sarason, I. G., Sarason, B. R., and Shearin, E. N. (1986). Social support as an individual difference variable: Its stability, origins, and relational aspects. J. Person. Soc. Psychol. 50(4): 845-855.

Slavin, L. A., and Rainer, K. L. (1990). Gender differences in emotional support and depressive symptoms among adolescents: A prospective analysis. Am. J. Comm. Psychol. 18(3): 407-421.

Slavin-Williams, R. C., and Berndt, T. J. (1990). Friendship and peer relations. In Feldman, S. S., and Elliott, G. R. (eds.), At the Threshold: The Developing Adolescent. Harvard University Press, Cambridge, pp. 277-308.

Sroufe, L. A., and Fleeson, J. (1986). Attachment and the construction of relationships. In Hartup, W., and Rubin, Z. (eds.), Relationships and Development. Erlbaum, Hillsdale, NJ, pp. 51-71.

Uchino, B. N., Cacioppo, J. T., and Kiecolt-Glaser, J. K. (1996). The relationship between social support and physiological processes: A review with emphasis on underlying mechanisms and implications for health. Psychol. Bull. 119(3): 488-531.

Vaux, A. (1985). Variations in social support associated with gender, ethnicity, and age. J. Soc. Issues 41: 89-110.

Windle, M. (1992). A longitudinal study of stress buffering for adolescent problem behaviors. Develop. Psychol. 28(3): 522-530.

Youniss, J., and Smollar, J. (1985). Adolescents Relations with Mothers, Fathers, and Friends. University of Chicago Press, Chicago. 